\title{
Exploration of Talent Training Mode by Combining Disciplinary Competition and Innovative Training
}

\author{
Lei Yang, Xin Song, Nan Wu, Li Wang \\ College of Engineering and Technology \\ Tianjin Agricultural University, Tianjin, China \\ yanglei2016@tjau.edu.cn
}

\begin{abstract}
This paper takes the scientific competition as the breakthrough point and the innovation training as the inheritance, in order to realize the echelon development of students' abilities, to establish a benign interactive development mode of "practice reform-disciplinary competition-innovation training", and to establish a teaching model of "promoting learning by competition, integrating practice and competition". The quality of innovative applied talents can be improved by combining disciplinary competition and innovation and entrepreneurship training with regular teaching links, and by deepening the reform of curriculum system and teaching content.
\end{abstract}

Keywords-scientific competition; innovation training; innovation ability; practical teaching

\section{INTRODUCTION}

Colleges and universities have an unshirkable responsibility for cultivating innovative talents. Integrating innovation and entrepreneurship education into the talent training system requires innovative reforms from training objectives, training programs to teaching models[1]. Colleges and universities should focus on improving the quality of personnel training, focus on the innovative talent training mechanism, promote the synergy of teaching, research, and practice to break through the weak links in talent cultivation, and to enhance students' innovative spirit, entrepreneurial awareness, and innovative entrepreneurship. Moreover, colleges and universities should adhere to innovation, lead entrepreneurship, entrepreneurship, take the initiative to adapt to the new normal of economic development, accelerate the cultivation of innovative and entrepreneurial talents with large scale, innovative spirit and courage to participate in practice, establish a talent training model that integrates innovation and entrepreneurship education with professional education, and complements knowledge and action to basically form a system of innovation and entrepreneurship in higher education institutions that integrates classroom teaching, independent learning, intensive practice, guidance and assistance, and cultural leadership and achieve innovation and entrepreneurial talent training to match social needs and development[2].

II. OVERALL CONSTRUCTION PLAN

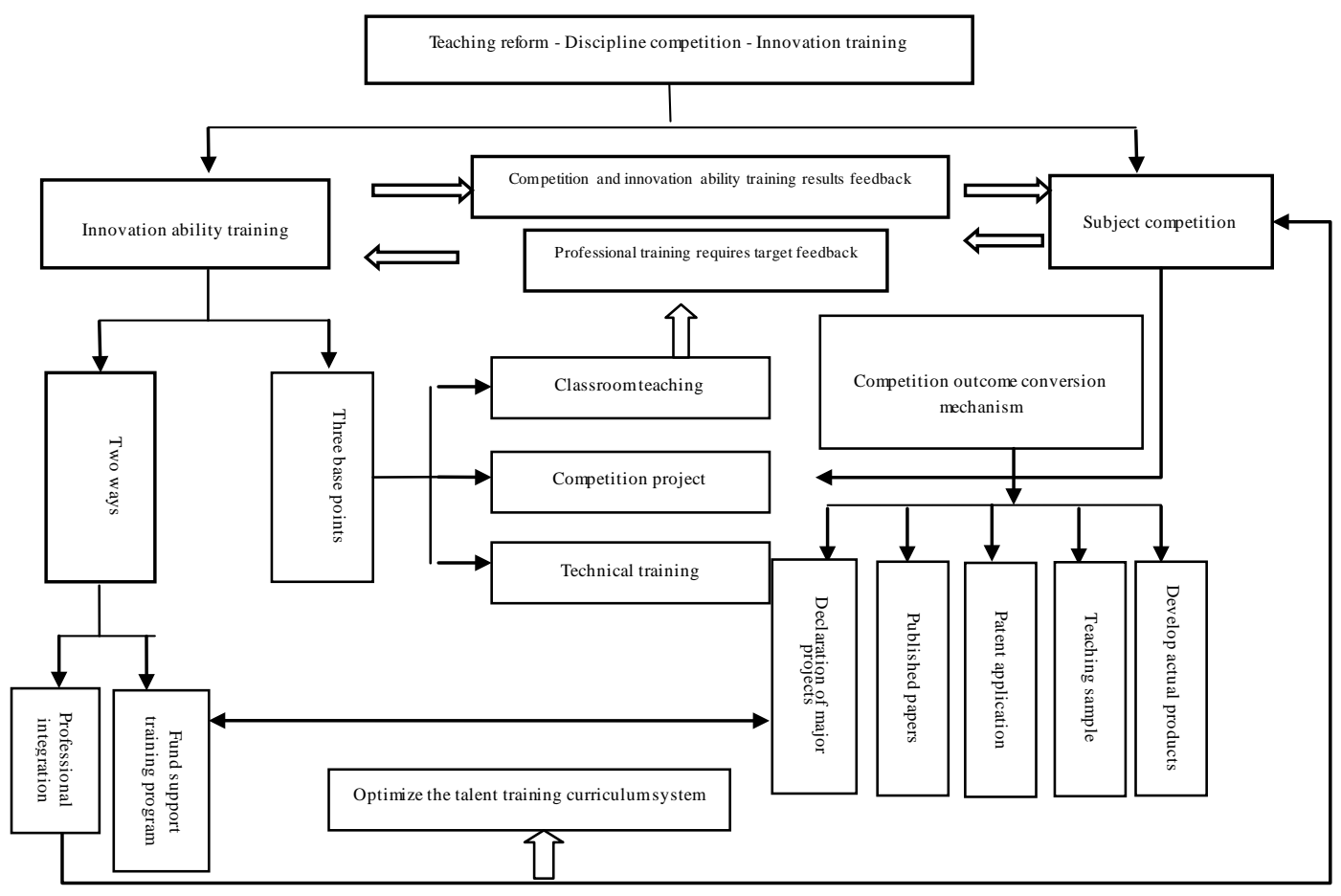

Fig. 1. Overall plan

Fund Project: Education and Teaching Research and Reform Project of Tianjin Agricultural College: Training the Innovative Ability of Applied Talents with Competition as the Carrier (Project No.: 2016-A-02) 
The "three basic points, two paths" talent training mode of the innovation competition, that is, the three basic points of classroom teaching, competition projects and technical training should be based to implement an innovative talent training model with professional integration and fund support (see Fig. $1)$.

\section{THE MAIN CONTENT OF THE INNOVATION ABILITY TRAINING} MODEL

\section{A. Three basic points}

First, classroom teaching should be the basis for the cultivation of innovative talents. Although the main purpose of the innovation competition is to cultivate the ability to innovate, the most basic still is to examine the mastery and application of basic theories, basic knowledge and skills. Classroom teaching is the main way to acquire and form knowledge, theory and skills. Therefore, colleges and universities must give full play to the basic role of classroom teaching in the cultivation of innovative talents. In the curriculum design, colleges and universities should pay attention to the arrangement of basic courses, highlight the importance of practical teaching, and ensure free choice of elective courses; and in the training program, colleges and universities should focus on the ability of students to actively learn and scientific thinking, embody the "people-oriented"concept.

Second, the competition project should be used as a carrier for the cultivation of innovative talents. Each competition project is a practical process of deep understanding, systematic organization and creative play of knowledge. On the basis of closely combining classroom teaching, all kinds of innovation competitions stimulate students' theoretical connection with practice and independent exploration. By discovering problems and solving problems, cultivating students' interest in learning and enhancing self-confidence in learning are an effective way to cultivate innovative ability[3]. Therefore, it is necessary to establish and improve the project system of the innovation competition by combing the categories of various competition projects and combining the actual situation of the school, and systematically cultivating students' innovative ability.

Third, technical training should be used as a means of training innovative talents. Creative improvement is the result of the simultaneous development of knowledge, skills and strategies. The process of cultivating innovative ability through the innovation competition is essentially a process in which students comprehensively learn theories, formulate reasonable technical solutions, and creatively solve problems. Among them, the technical solution is the key[4]. Therefore, it is necessary to strengthen the technical training in the competition project, which is the core of the cultivation of students' innovative ability. The three basic points of classroom teaching, competition project and technical training are independent and closely related, and support the innovation ability of college students from different angles and stages. The interaction between the three together constitutes a relatively complete and three-dimensional innovation ability training system.

\section{B. Two paths}

Path 1: Professional integration promotes innovation.

Colleges and universities should take "professional integration" as the main line, encourage students to try to break through the constraints of professionalism, adhere to the concept of "combining experiment and innovation, combining inspiration and motivation, and combining innovation ability training with scientific research", should start from the aspects of teaching system, curriculum system, teaching mode, teaching resource environment, open integrated innovation practice platform and teaching team construction, build teaching elements that meet the needs of high-quality personnel training, and promote the professional innovation ability of compound talents.

\section{Path 2: Fund support promotes development}

Colleges and universities should rely on innovative fund projects to train students' academic innovation ability, depend on the college students' innovation and entrepreneurship training program, that is, to apply for the university-level and national-level college students' innovation and entrepreneurship training programs with the competition plan to achieve the amplification and radiation effects of the students' competition results.

\section{IMPLEMENTATION OF THE INNOVATION CAPACITY TRAINING} MODEL

\section{A. Optimize the training system for talents with the goal of practicing innovation and training}

Whether the subject competition is focused on the examination of basic knowledge and skills or the encouragement of innovation, its foundation is always based on the basic theory, basic knowledge and basic skills of the subject, and this knowledge, theory and skills are mainly from classroom teaching. Therefore, in order to cultivate students' innovative ability through subject competition, it is necessary to grasp the important pivot of classroom teaching and further play the basic role of curriculum teaching. The research work is planned to combine the practice, carefully study the relationship between the discipline competition and the cultivation of innovative talents, and revise the talent training plan to form a systematic innovative talent training program. For example, colleges and universities can improve and promote the successful teaching reform model of competition courses such as electronic design and mathematical modeling, revise the training plan, curriculum syllabus and experimental outline, set up independent competition elective courses, and combine the curriculum design, graduation design and other practical teaching links, actively research and design new competition projects, enrich and improve the discipline competition system, and build the core carrier for the discipline competition practice platform. 
B. Establish a training base for innovative education and discipline competition, build a platform for training practical innovation ability, improve the operation mechanism of the innovation base, and improve the innovation system platform.

1) Standardization and institutionalization of management. Colleges and universities should formulate corresponding rules and regulations for teaching management, improve relevant quality standards and technical specifications, ensure that all work is carried out in an orderly manner, and conduct process management of screening and standardization of competition projects to provide guarantee for the scientific development of innovation competition.

\section{2) The construction of instructors.}

In the subject competition, the students are the main body, the teachers are the guarantee, and the students' innovative ability training depends on the help and guidance of the teachers. Therefore, how to establish a team of instructors with strong sense of responsibility, high level of business and reasonable structure is the key to the cultivation of students' innovative ability. Colleges and universities should select and train a group of teachers with strong scientific research ability, high technical level and strong sense of responsibility, and form a discipline competition steering group to provide students with strong knowledge guidance and technical support for participating in the competition. In addition, colleges and universities should also instruct teachers to use their spare time to tutor students, and provide corresponding series of elective courses according to the needs of the subject competition, strengthen basic knowledge, introduce new subject knowledge, broaden students' knowledge, cultivate students' ability to analyze and solve problems, improve students' understanding of academic competitions and competitiveness in competitions[5][6]. And colleges and universities should also encourage teachers who participate in academic competitions to give certain incentives and rewards to teachers who offer courses in the corresponding disciplines, give priority to the teacher training in the guidance competition, so as to fully mobilize the teachers to actively participate in the academic competition activities, closely combine the curriculum teaching activities with the academic competition activities, establish interaction within and outside the classroom, promote the comprehensive development of the teaching style and the style of study, and focus on cultivating students' innovation awareness and ability.

\section{3) Implement an open laboratory system}

With the active development of academic competitions and extracurricular science and technology activities, the opening of in-class teaching experiments and extracurricular interestbased experiments has gradually become more and more flexible[7]. Therefore, the open management model of the laboratory is particularly important. The open experimental center often has to undertake the experimental teaching and related research work of the relevant experimental courses of various departments. At the same time, it is necessary to establish a complete management system, including equipment management, student experiment code, safety management, instructor code, etc. It is especially important that the open experimental center must have a mature network appointment management system and a full-fledged part-time experimental teacher team, equipment maintenance personnel and experimental technicians to implement full-time open management. Under the influence of open conditions, the open experimental center must be based on the new experimental center management model to achieve resource sharing.

\section{Establish an effective outcome transformation mechanism}

Establishing an effective conversion mechanism for competition results is a long-term mechanism to promote the sustainable development of innovation competitions. The use of the display of results to play a diffusion effect can better promote the development of innovation competition. It is necessary to establish and improve the results conversion mechanism to provide channels for transformation of excellent scientific research works, such as paper publications, patent applications, etc.; the excellent programs in the subject competition can be transformed into practical teaching cases; the excellent products produced in the innovation competition can be transformed into projects with practical application value through the multi-channel exchange and cooperation of government, industry, research and research, and brought to the market to realize its value of promoting economic and social development.

\section{CONCLUSION}

The benign interactive development model of the combination of subject competition and entrepreneurship training can improve the quality of innovative entrepreneurial and applied talents. Disciplinary competition is the best way to improve students' comprehensive professional ability, and further innovation and entrepreneurship training will help the inheritance of college students' academic competition and realize the development of students' ability. Therefore, establishing a talent training model of "synchronizing with competition, training and integration", combining discipline competition and innovation and entrepreneurship training with regular teaching links, deepening the reform of curriculum system and teaching content are of great significance to promoting China's realization of the goal of training innovative and entrepreneurial talents.

\section{REFERENCES}

[1] Zhu Hangyu \& Li Jianli. Research on the Cultivation of College Students' Innovative Ability Driven by Discipline Competition and Scientific Research Projects[J].Henan Education,2018(7):38-40. (In Chinese)

[2] Zhuang Mingzhu. Discussion on the Training Mode of Academic Competition Driving College Students' Innovation Ability[J]. Education Modernization. 2018(1):56-58. (In Chinese)

[3] Li Dong. On the Cultivation of Students' Practical Innovation Ability through Subject Competition[J]. Education Modernization.2017(47):3637. (In Chinese)

[4] Wang Li, Li Yangliang, Liu Liangwen, Zhang Deqin \& Du Xuefei. Research on the Cultivation of College Students' Innovation and Entrepreneurship Based on Discipline Competition. Education and Teaching Forum[J].2017(23):54-55. (In Chinese)

[5] Wang Fenglian, Wang Banglun, Xie Rongjian \& Zhu Xiebin. Research on the Incentive Mechanism of University Discipline Competition Based 
on the Cultivation of Innovative Practice Ability. Journal of Chongqing University of Science and Technology (Social Science Edition)[J].2017(2):104-107. (In Chinese)

[6] Wang Erkun, Li Xuan, Li Yufeng, Shao Qingliang \& Xu Hao. Cultivating Practical Ability Based on Discipline Competition and Innovation Plan Project[J].Lab Science,2015(5):181-183. (In Chinese)
[7] Fan Li, Ding Zhuyu, Tang Wei \& Deng Tao. Building a Multidisciplinary Competition Platform to Cultivate Practical and Innovative Talents[J].Journal of Southwest China Normal University(Natural Science),2016(8):178-182. (In Chinese) 